\title{
The Construction of Blended Teaching Mode of Cooking Technology Course Under the Background of "Gold Course"
}

\author{
Li Rui ${ }^{1}$, Pang Lianrong ${ }^{2}$ \\ ${ }^{1}$ Department of Food Science and Engineering, Lingnan Normal University, Zhanjiang, China \\ ${ }^{2}$ Department of Business Management, Lingnan Normal University, Zhanjiang, China
}

Email address:

lnsylirui@qq.com (Li Rui),806834317@qq.com (Pang Lianrong)

To cite this article:

Li Rui, Pang Lianrong. The Construction of Blended Teaching Mode of Cooking Technology Course Under the Background of "Gold Course". Teacher Education and Curriculum Studies. Vol. 6, No. 1, 2021, pp. 18-22. doi: 10.11648/j.tecs.20210601.14

Received: January 21, 2021; Accepted: January 31, 2021; Published: February 26, 2021

\begin{abstract}
Under the trend of "Internet+Education", the online and offline blended teaching mode has become an important direction of teaching reform. This article takes the course "Cooking Technology" as an example to build an online and offline blended teaching mode, and investigates the application of blended teaching in the teaching of applied undergraduate courses. Using empirical analysis and interview methods, the article found that the curriculum teaching of "Cooking Technology" has insufficient combination of theory and practice, single teaching mode, poor teaching effect, and heavy teaching tasks. Base on the principle of student-centered, pedagogical coherence, integration of theory and practice, this article designs the blended teaching activities for the "Cooking Technology" course from the three major links, which is the pre-course phase, in-class stage and afterschool phase. This article puts forward the issues that should be focus on interaction in blended learning and teaching, establishing a reasonable and sound appraisal method, pay attention to the percentage of online instruction used, so as to provide reference and reference for the construction of "golden courses" of culinary majors and other majors. Finally, the study found that the blended teaching can better cultivate students' autonomy in learning and solve the basic problems that most students are not interested in learning.
\end{abstract}

Keywords: Gold Class, Blended Learning, Cooking Technology, Teaching Reform

\section{Introduction}

Gold courses, which are first-class teaching courses, have been actively responded to by universities to build different types of gold courses since the concept of gold courses was proposed by the Ministry of Education in 2018. Advanced, innovative and challenging are the main characteristics of the "Golden Lesson" [1]. At present, many scholars in China have explored the issue of creating golden lessons from different perspectives. Bian Chun took food biochemistry course as an example to explore the design and practice of blended teaching mode [2]. Xu Zhiguo studied the application of blended teaching in electronic information courses using a flipped classroom approach based on an online teaching platform and online teaching resources [3]. Liu Limin explained the problems existing in the reform of blended teaching and took the course Modern Logistics as an example to practice the reform of blended teaching based on SPOC [4]. In different links of the teaching process, teachers and students were used to participate together, and online and offline methods were combined to optimize the teaching work. Du Xinzheng designed the application of the "four-in-one" blended teaching mode of "MOOC+SPOC+ FLIP Classroom $+\mathrm{CBE}$ " in the course of financial engineering [5]. Students use MOOC teaching resources and SPOC platform to complete the preclass learning and post-class consolidation of learning contents and complete the construction of knowledge in face-to-face lectures. Luo Hongyu constructed a blended teaching mode for the course "Sensor Principle and Application" with the help of Blue Ink Cloud Class, and used the teaching platform of Blue Ink Cloud Class to conduct teaching activities before, during and after class [6]. It can be seen that by building golden courses, we can better ensure the quality of teaching and learning in universities and implement the educational goal of 
"establishing moral education for people". Therefore, this article takes the Cooking Craft course as an example to build a blended teaching mode and create an online and offline blended "Golden Class".

\section{Research Object}

In the process of creating a gold course, it is important to choose the appropriate approach based on the characteristics of the different courses. The article focuses on Cooking Technology Course. As a core course of the Culinary and Nutrition Education major, the course aims to lay a solid foundation for students to engage in culinary research and culinary technology, as well as business management in the future [7]. The course covers a wide range of subjects and studies, so the content and knowledge of the course is taught in a large number of ways and is highly instructive in practice. The current course teaching of Cooking Craft has the problems of insufficient combination of theory and practice, single teaching mode, poor teaching effect and heavy teaching task. Building a blended online and offline teaching model for Culinary Craftsmanship can well solve the above teaching problems.

\section{The Construction of a Blended Online and Offline Teaching Model}

\subsection{Principle of Construction}

\subsubsection{Principle of Student-centered}

Blended teaching is based on constructivist learning theory, which emphasizes the learner's initiative in learning and the process of constructing original knowledge and experience. Therefore, in building an online and offline blended teaching model, it is necessary to adhere to the student-centered principle of teaching and learning, and to stimulate students' autonomy and interest in learning to the greatest extent, rather than simply instilling knowledge into students. Teachers should do a good job of analyzing the teaching objects and guiding students through a series of knowledge construction processes such as independent learning, problem identification, and extension. In short, adherence to student-centered principles is a paradigm shift from a transmission-reception model to a guided-discovery model of teaching and learning.

\subsubsection{Principle of Pedagogical Coherence}

The principle of pedagogical coherence is based on the concept of outcomes-based education. The concept of outcome-oriented education reverses the design of teaching activities and curriculum development by taking the teaching objectives as the starting point, so that the curriculum design, teaching activities, and learning assessment conducted by teachers must closely follow the intended teaching objectives and serve the achievement of the teaching objectives when conducting blended teaching, whether online or offline [8]. The online and offline blended teaching model expands the forms in which teachers can carry out their teaching activities and places higher demands on their ability to design instruction.

\subsubsection{Principle of Integration of Theory and Practice}

Most professional training programs put forward the dual objectives of theoretical and practical skills for students, and it is particularly important to adhere to the principle of integrating theory and practice in teaching and learning for application-oriented majors [9]. And there is an interaction between theory and practice; theory can guide practice, and practice in turn can consolidate and develop theory. When constructing a blended teaching model, teachers should firstly focus on the connection between course knowledge points and practical operations, secondly build visual online teaching resources, and thirdly model teaching through practical operations.

\subsection{Construction of the Teaching Model}

\subsubsection{Course Content Analysis}

Course content analysis the process of teachers' comprehension and understanding of teaching content, mainly includes the sorting out of knowledge points, the determination of teaching objectives and the choice of teaching forms. By analyzing the course content in advance, teachers are able to better grasp the content of the lectures, subdivide the course content, and adopt the appropriate teaching format for different knowledge points as well as teaching objectives, thus guiding the design of blended teaching models and activities [10]. Table 1 shows the course content analysis using the teaching module of Culinary Prep Process as an example.

Table 1. Content analysis of teaching culinary prep processes

\begin{tabular}{llll}
\hline Course Content & Knowledge Point & Teaching Objectives & Teaching Format \\
\hline & $\begin{array}{l}\text { Meaning and types of pre-processing } \\
\text { The role and principles of pre-treatment }\end{array}$ & $\begin{array}{l}\text { Understanding the concepts and types of pre-processing } \\
\text { Clarity on the role and principles of pre-treatment } \\
\text { The concept and role of pre-treatment methods such as } \\
\text { decoding flavor, sizing, hanging paste and powdering, } \\
\text { and mastering their operation process }\end{array}$ & $\begin{array}{l}\text { Online learning, classroom discussions } \\
\text { Online learning, classroom discussions }\end{array}$ \\
& Typical pre-treatment methods & $\begin{array}{l}\text { Online learning, classroom discussions, } \\
\text { classroom demonstrations }\end{array}$ \\
$\begin{array}{l}\text { Cooking } \\
\text { pre-processing }\end{array}$ & $\begin{array}{l}\text { Typical Preliminary Mature } \\
\text { treatments such as gas steaming, blanching, oiling and } \\
\text { frying, and master the process of their operation }\end{array}$ & $\begin{array}{l}\text { Online learning, classroom discussions, } \\
\text { classroom demonstrations }\end{array}$ \\
& $\begin{array}{l}\text { Treatment } \\
\text { Application of pre-processing in the } \\
\text { preparation of dishes }\end{array}$ & $\begin{array}{l}\text { Knowledge of the practical application of pre- } \\
\text { treatment processes in preparation dishes }\end{array}$ & $\begin{array}{l}\text { Online learning, classroom } \\
\text { demonstrations }\end{array}$ \\
\hline
\end{tabular}




\subsubsection{Online Teaching Resources Construction}

The construction of online teaching resources is a prerequisite to ensure that students complete high-quality online learning. Teachers upload corresponding courseware or teaching materials to the teaching platform for students to learn according to the knowledge points broken down by course content and create online test questions to test and consolidate students' learning results. In addition, because the course of Cooking Technology is closely related to practical operation, teachers can choose to use teaching video as the carrier of teaching content when building online teaching resources. Currently, there are relevant online open courses of Cooking Technology on China University MOOC [11], and teachers can also make their own micro-class videos. Choosing instructional videos as a form of online instruction allows for visualization and contextualization of the content, increasing students' understanding of the application of knowledge and interest in learning.

\subsubsection{Design of blended Learning and Teaching Activities}

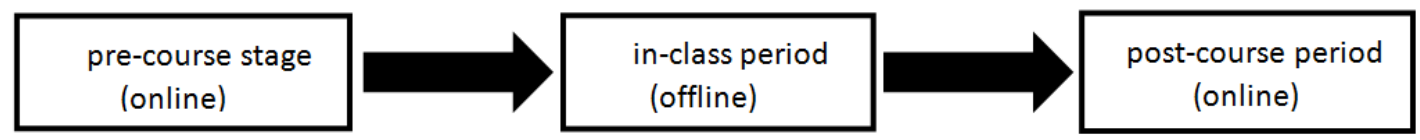

Figure 1. Flow design of blended teaching activities.

Table 2. The design of blended teaching activities.

\begin{tabular}{llll}
\hline & 1. Assignment of teaching tasks & 1. Explanation of important and difficult points & 1. Assign to a task \\
teachers & 2. Upload courseware and videos & 2. Organization of the discussion & 2. Teachin interventions \\
& 3. Post pre-course test questions & 3. answer questions and clear up confusion & 3. Reflections on Teaching \\
& 1. self-directed learning & 1. put questions & 1. Complete the assignment \\
students & 2. Complete the test questions & 2. Classroomn Discussions & 2. After-class consolidation \\
& 3. query & 3. On-site observation & 3. Feedback \\
\hline
\end{tabular}

\section{(i). Pre-course Phase}

The pre-course phase of the blended learning and teaching activities is mainly conducted online using the teaching and learning platform. Teachers first create an online course on cooking technology through smart teaching tools such as Rain Classroom and Superstar Learning Pass, and set it up to be open only to students in the class in which it is taught, then assign corresponding teaching tasks and pre-course tests on the platform according to the teaching objectives of different chapters in the course. Take the chapter on the selection and identification of cooking ingredients as an example, the chapter requires students to understand the meaning, requirements and quality standards of cooking ingredients selection, master the principles and methods of cooking ingredients selection, and be able to conduct sensory identification of cooking ingredients according to the requirements of the cooking process. Therefore, teachers can assign teaching tasks and test questions on how to understand the extensiveness and strictness of Chinese cooking ingredients selection, what are the basic principles of cooking ingredients selection, what aspects of sensory identification usually include and their common methods, and upload courseware and videos related to the course chapters for students to study, and the content of the videos and courseware should focus on the introduction and identification of cooking ingredients. After the teacher completes the online class building, students are required to access the online course. Students are guided by the teaching tasks to independently study the teaching materials uploaded by the teacher, complete the practice problems assigned by the teacher, and can ask questions they encounter during the independent study on the platform to seek answers from the teacher or other students. The teaching and learning activities in the pre-course stage are the process of students' independent learning before class. This process can improve students' autonomy in learning and enable them to have a basic understanding and mastery of the lecture content, thus facilitating teachers' teaching in the mid-course stage.

\section{(ii). In-class Phase}

The in-class phase of blended learning activities takes place primarily offline. In the classroom, the teacher first briefly composes the teaching content, then focuses on the important and difficult points of the teaching content, raises questions and organizes students to discuss; students answer the teacher's questions through discussion, and at the same time raise questions in the process of discussion, and finally the teacher answers and solves the problems. Taking the teaching module on cooking pre-processing as an example, teachers can start with a brief lecture on the meaning and types, roles and principles of cooking pre-processing, while the explanation of the key points and the questions asked should involve deepening and expanding the knowledge, such as the difference between oiling and frying, what is the effect of battering and hanging on the ingredients, and what ingredients need preliminary cooking treatment, so as to inspire students to think and inquire. For some practical teaching modules, such as knife craft, teachers can conduct practical demonstration teaching, and demonstrate the movement standards and technical essentials of straight knife method, flat knife method, slanting knife method and graver knife method through practical operation in the culinary training 
room, so that students can learn and understand the relevant knowledge more intuitively [12].

\section{(iii). After-school Phase}

The after-school phase of blended learning activities takes place primarily online. Teachers assign post-class assignments and exercises on the teaching platform according to the content of the lectures and require students to complete them on time for the purpose of consolidating their learning. Since cooking technology is a comprehensive and applied technical discipline, its research content involves other disciplines such as culinary chemistry, culinary ingredients, nutrition and other knowledge, and also has a strong significance in guiding practice, teachers can link the after-school assignments of cooking technology with the knowledge points of other related courses, so as to promote the students' integration and application of knowledge [13]. Take the teaching chapter on the water heating treatment process as an example, the post-lesson assignments assigned by the teacher could be to explore the effect of the water cooking method on the nutrients in the cooking ingredients, what chemical reactions occur during the water cooking process, and to answer what changes in the sensory qualities and physicochemical properties of the cooking ingredients after the water heating treatment, and what the characteristics of the finished product are, in conjunction with the practical cooking skills class. In addition, because learning before and after class in blended teaching activities takes place online, individual student learning process data such as the length of time spent studying online teaching resources and the results of completing online tests and assignments can be counted and analyzed through the platform, and teachers can use these data to understand the overall learning situation of students and conduct interviews or communication with individual students who are learning less effectively, thus enabling teaching intervention. Finally, teachers can collect feedback from students during the blended learning process, as well as reflect on the problems in the teaching process to better guide the next teaching activities.

\section{Analysis of Problems in Blended Learning Practice}

\subsection{Focus on Interaction in Blended Learning and Teaching}

Yu Jianhua [14] et al. point out the interaction between students, individual behavior, and learning environment in blended learning based on Bandura's "interactive determinism". Teachers need to pay attention to the interaction of these three in the process of blended teaching and learning, and take corresponding measures to promote this role in a favorable direction, including encouraging and monitoring students' online self-directed learning to promote students' active learning behavior into the improvement of students' individual cognitive ability and learning level; creating a good classroom atmosphere and learning environment, including the construction of online teaching resources and the guidance of offline classroom dis

\subsection{Establishing a Reasonable and Sound Appraisal Method}

Reasonable and sound assessment methods can motivate and monitor students' learning behaviors, and provide teachers with references and bases for understanding students' learning, which is a guarantee for the smooth running of teaching and learning activities [15]. When assessing students' learning, teachers should not only pursue summative assessment, but also adopt the approach of "formative assessment + summative assessment". In addition to the final written test results, they should also consider the test practice scores, the number of questions answered and the time spent on online learning, which can reflect students' learning attitudes and effectiveness, so as to make the assessment method more reasonable and perfect, and better guide students' learning in the blended teaching mode.

\subsection{Pay Attention to the Percentage of Online Instruction Used}

Teachers should be mindful of the proportion of online instruction used when building a blended model to avoid the two extremes. When the proportion of online teaching is used too little, it tends to make it a formality, making the online teaching platform just serve as a notification and attendance, and not really playing its role; and if it relies on online teaching, it may be detrimental to teachers' supervision of students' learning activities, and reduce the effectiveness of classroom teaching [16]. In addition, the proportion of online and offline teaching use can be flexibly arranged for different types of courses, for example, for general education courses, the proportion of online teaching use can be appropriately increased; for professional core courses, more attention should be paid to classroom teaching at the mid-course stage.

\section{Conclusion}

The construction of blended teaching mode can improve the quality of course teaching, enhance students' learning autonomy and improve the utilization of teaching resources. This article bases on the principle of student-centered, pedagogical coherence, integration of theory and practice, which also to design the blended teaching activities for the "Cooking Technology" course from three major links. The study found that the blended teaching can better cultivate students' autonomy in learning and solve the basic problems that most students are not interested in learning. With the development of modern education technology and education concept, the construction of online and offline blended teaching mode is more reasonable and mature. As an important direction of teaching reform, the construction of blended teaching mode will be an important means to create "golden courses", which will be more widely used and popularized by educators. 


\section{Acknowledgements}

This article was supported by Lingnan Normal University's Teaching Reform Project "Practice and research of micro-class-based flipped classroom teaching mode in cooking skills teaching "(2018, LSJGMS1835), Lingnan Normal University's Online Open Course Project "Cooking Technology and Famous Dishes Appreciation" (2018).

\section{References}

[1] Wu Yan. Building China's "Golden Course" [J]. China University Teaching, 2018 (12): 4-9.

[2] Bian Chun, Jia Zhen. A preliminary investigation of blended teaching in food biochemistry course in the context of golden course construction [J]. Journal of Higher Education, 2019 (25): 116-118.

[3] Xu zhiguo, Chen zhengyu, Yang Li. Research on blended teaching of electronic information courses based on online platform [J]. Integrated Circuit Applications, 2019, 36 (12): 25-27.

[4] Liu limin. Practice of blended teaching reform based on SPOC - taking Modern Logistics as an example [J].

[5] Du Xinzheng, Gu Xiaoyan, Xiong Fali. Research on the design and application of "four-in-one" blended teaching mode in the training of financial engineering professionals in applied undergraduate institutions [J]. Jiangsu Science and Technology Information, 2019, 36 (30): 66-69.

[6] Luo Hongyu. Research on the innovation of blended teaching mode in applied undergraduate colleges and universities--Take Sensor Principles and Applications as an example [J]. Vocational and technical education, 2018, 39 (17): 34-36.
[7] Li Chao, Chen Fuyu, Hao Zhiguo et al. Some attempts to produce courseware for "Cooking Craft" [J]. Journal of Jilin Agricultural Science and Technology College, 2012, 21 (04): 79-80.

[8] Wu Yanhua, Fan Huihui, Qian Rong et al. Design and practice of blended instruction in genetics under the principle of coherent constructs [J]. Genetics, 2019, 41 (05): 439-446.

[9] He Chunmei. Process evaluation, achievement goal orientationand learning engagement: mechanism and path $[\mathrm{J}]$. Exploration of higher education, 2020 (11): 36-4.

[10] Luo Wei, Wang Ling. Teaching reform of C language course conforming to engineering education certification standard $[\mathrm{J}]$. Computer age, 2017 (2): 79-81.

[11] Jin Miao, Gao Dongmei. Practical research based on online and offline hybrid teaching mode. Health Vocational Education, 2020, 38 (18): 86-87.

[12] Zhao Dan. Practice and effect analysis of online teaching. Education Teaching Forum, 2020 (43): 283-284.

[13] Liu Ping, Liao Kangli. Research on employment and entrepreneurship education in local universities from the perspective of entrepreneurial endowment [J]. Education and occupation, 2012 (15): 81-82.

[14] Yu jianhua, Liang dongrong. Analysis of interaction in blended learning and teaching [J]. Teaching and Management, 2019 (18): 16-18.

[15] Wang Shusheng, Shao Hua. Content construction and practice exploration of College Students' innovation and entrepreneurship psychology [J]. Forestry teaching, 2020 (07): 93-96.

[16] Bai Yu. Research on entrepreneurship education system based on College Students' entrepreneurial intention [J]. China market, 2016 (25): 74-75. 